\title{
Changes in the Activities, Functions, and Roles of Public Health Educators
}

\author{
Robert A. Bowman, Ph.D.* \\ The University of Michigan
}

\begin{abstract}
Accounts of early activities of public health educators, statements of the American Public Health Association on the qualifications and functions of these educators, and studies concerned with their responsibilities, functions, work, or roles are reviewed. These point up the three major foci in public health education over time in the U.S., viz, dissemination of information, community organization, and health behavior and program planning. Functions of public health educators in emerging settings for practice are presented and the implications of this movement (i.e, movement of health educators into non-traditional settings) for the public health education profession are discussed.
\end{abstract}

Some parallels can be noted in (a) the changes which have occurred in the needs for health education and information expressed by the U.S. public, consumers, and health professionals and (b) the changes in the functions and activities of public health educators. In early years when health knowledge was locked up in the minds of a small number of the more educated citizenry, principally physicians, nurses, and dentists, and little had been printed about health matters, health educators helped meet the expressed need for health information. Later as it became apparent that the solution of health problems required organization of resources and efforts and "learn by doing" became a focus as a method of education, health educators became community organizers. In more recent years they have become health behaviorists and program planners in response to social legislation and as they attempt to adapt health education programs to changes in life styles, the needs of various ethnic groups, an apathetic public, and the needs expressed for health educator expertise by other health professionals.

* Professor of Health Education, Department of Health Behavior and Health Education, School of Public Health, The University of Michigan, 1420 Washington Heights, Ann Arbor, MI 48109. 
Obviously the evolution of the public health educator, which began in the U.S. during the first half of the nineteenth century, has been a very gradual process. In the early years when the public made evident its great interest for more information about the care of the human body and the common health problems of the day, and when public health leaders of that period urged various approaches to assure a society enlightened on health matters, ${ }^{8,24,32,25}$ the health educators of the time (most with backgrounds in writing or journalism, nursing, or social work) responded. Their principal activities were the preparation and delivery of talks and lectures and the preparation of leaflets, pamphlets, newsletters, news releases, films, and exhibits. These remained as dominant activities through the first half of the twentieth century during which many health administrators advocated the use of popular education as an instrument of prevention to combat the high incidence of tuberculosis and other communicable diseases, high infant and maternal mortality rates, and poor sanitary conditions in communities. $7,16,36,38$

While dissemination of information in the belief that knowledge about health problems would assure better health practices satisfied the public's expressed desire for health knowledge and proved a useful method for combating diseases and health problems, a small core of health educators began to realize that mere presentation of facts did not assure motivation and that the goal of improved health practices and attitudes was not being met. So, about 1917 a new philosophy of health education was conceived which emphasized the involvement of the learner in the learning process. ${ }^{22}$ As a result, the provision of learning experiences related to health and direct work with people in face-to-face settings to bring about these experiences became principal functions of many health educators while others continued chiefly as disseminators of health information. Persons prepared to teach were sought to fill health education positions rather than writers, lecturers, or public relations personnel as in the earlier period.

Community organization became a major function of public health educators a decade or so later. While the organization of citizen groups to bring about better health conditions and necessary health legislation antedates most of the origins of health education in the U.S., it was not until the 1930s that community organization for health education took form as a definite part of health education programs and as a function of the public health educator. ${ }^{16}$ Working with community groups for the improvement of health was "an idea whose time had come," according to Derryberry ${ }^{20}$ whose appointments in the Public Health Service, as senior public health statistician in 1936 and as chief of health education services from 1942 to 1963 , 
provided a vantage point to observe national trends.

By the 1940 s community organization had become the principal method of health education and a major function of public health educators. ${ }^{28,28}$ Connolly, ${ }^{16}$ who pioneered in Detroit, had found it an effective method for adult health education. Morgan ${ }^{27}$ and others directed programs that provided sound evidence of its effectiveness as a method. These had a major impact on health education practice throughout the U.S. Testimony to its acceptance as a successful method can be noted in (1) legislation enacted in the 1950s and 1960 s requiring consumer organization and participation in programs such as those characterized as Urban Renewal, Model Cities, and Neighborhood Health Centers, and (2) its use by the Peace Corps as a principal approach in developing countries. In all of these, "learning through participation" was considered a principal objective.

Community organization continued as the principal function of public health educators until the outpouring of national legislation in the 1960 s reflecting social change which brought about major changes in the delivery of health services. These in turn brought about major changes in the duties and responsibilities of many public health workers including public health educators.

\section{Emphases and Trends in Functions of Health Educators}

Thus, until recently the major emphases in public health education, as outlined above, have been (1) dissemination of health information, just "the facts" in the early years and "sugar-coated facts" or "facts dressed with emotions" ${ }^{23}$ beginning in the 1920 s when it became evident that mere presentation of facts did not assure motivation and that the goal of improved health practices and attitudes was not being met 22 and (2) community organization.

These emphases and their impact on the trends in functions of public health educators can be noted in the concerns and activities of the Public Health Education Section of the American Public Health Association, recently compiled by Rugen. ${ }^{31}$ They can be noted also if one examines the statements on the educational qualifications of health educators published over the years by the American Public Health Association. The first such statement in 1937 stressed the functions related to dissemination of information and the imparting of health knowledge. ${ }^{1}$ Subsequent revisions of the statement in 1943 and 1948 reflect the growing acceptance of community organization as a major emphasis in health education and the attempts to clarify the overall functions of public health educators as distinguished from school health educators. ${ }^{2,3}$

The 1948 revision added community to its title (Educational Qualifications of Community Health Educators) and represented a tremendous attempt to think through the functions of community 
health educators. Although 15 functions were detailed for "health educators in community-wide programs of health education," the report stressed that "they are not the functions of any one health educator and it is not expected that any one health educator will have special skills in all the knowledge areas involved." Prominence was given to functions relating to community organization for health education. Other functions stressed the role of the health educator in preservice and inservice training, consultation, adult education, school health education, and program planning and evaluation, as well as many aspects related to the dissemination of health information carried over from earlier years.

When the statement was revised in 1957, a further attempt to organize and delineate functions of public health educators was made. The title "Educational Qualifications and Functions of Public Health Educators" reflects this with the addition "and functions" and substitution of "public" for "community" health educator. The latter was an apparent attempt to point up the role of health educators in public health agencies as differentiated from the school setting. Functions were presented in three categories. Emphasis was given to program planning and evaluation which was made a separate category and given first listing. The second category grouped community organization, education methods, and public relations activities under the title of organization and promotion of health education. The third category, extension of health education through communication, contained a list of activities concerned with dissemination of information and made a special point of indicating that the public health educator worked with communication experts (writers, artists, and radio, TV, and audiovisual specialists) to do this. The latter appears to be an attempt to deemphasize the health educator stereotype as a projectionist, mass media specialist, and pamphlet writer. Surely, working with these specialists was not an innovation of the $1950 \mathrm{~s}$. The assistance of writers, artists, and public relations experts had been sought and their counsel and expertise put to work from the earliest days of health education, and the radio, audiovisual, and TV experts were welcomed as these technologies developed.

\section{The Behavional Approach and \\ Prognam Planning Emphases}

In the 1960s the Society for Public Health Education assumed the responsibility for stating criteria for professional preparation and functions of health educators formerly carried out by the APHA Committee on Professional Education as represented in the reports cited above. In a 1967 report an attempt was made by a SOPHE committee to differentiate the functions of community health educators with different levels of preparation - bachelor's degree and 
master's degree. 14 While little change is evident in stated functions of community health educators from those enumerated in the 1948 and 1957 statements previously summarized, the outline of areas of knowledge, concepts, and skills for community health educators in the report is representative of the considerable change in concepts which had occurred in the $1960 \mathrm{~s}$. There is special attention given to determinants of human behavior; the application of concepts of human behavior in program planning, development, and evaluation; evaluation of health education media and methods and their role in behavioral change; and study design and research on health behavior and health education.

It is possible that this report reflects the work of an earlier SOPHE committee charged with the responsibility of preparing a subject matter outline for the guidance of the APHA Professional Examination Service for use in developing professional examinations for health educators and other health workers. 35 This outline listed areas of knowledge and skill fundamental to public health education practice. It led off with the determinants of human behavior as represented in theory and research findings and their implications for learning. A second section focused on educational theory and research findings related to principles and theories of the learning process, the process of change, and group dynamics. Also included were strong sections on program planning and evaluation, educational methods, and research (especially the application of research findings to health education practice as related to health behavior).

Examination of these reports points up the trend toward more emphasis on the behavioral approach in health education, the health educator role in effecting changes related to health behavior as they concern individuals, groups, or organizations. This behavioral emphasis has supplanted for the most part community organization and dissemination of health information as major emphases in health education. But it is interesting to note the continued attention given (1) to community organization as a method for effecting change in individuals, organizations, or communities and (2) to the communication of health knowledge and instructional technology.

Studies on the Functions

of Public Health Educators

Apparently there was little concern about the activities, responsibilities, functions, work, or role of health educators in the early years as this specialty developed. This is not surprising since studies of public health workers' activities do not appear in the literature until the early 1930s when job analyses and time studies, employed previously in industry and government, were used to assess the activities of public health officers, nurses, and sanitarians. The few 
studies reported then are followed by a lapse of nearly 15 years until such studies appear again in the literature.'

Studies concerned with the functions of public health educators are summarized in Table 1. Although all were concerned with "functions" as so designated at present, many studies used other terminology such as duties, responsibilities, activities, work, or roles. The table indicates the principal methodology employed in each study, its universe, and the principal findings related to the functions of public health educators. Other findings reported in some studies, but not especially pertinent to this summary, have been omitted.

Principal Findings Reganding Roles and Functions. Examination of the table indicates that job analyses, time studies, and role perceptions are the three principal methodologies utilized over the years. Questionnaires have been developed and used in many of the studies for mail surveys or personal interviews with health educators.

When the principal findings reported for the 13 studies are examined, it is essential to keep in mind not only the differences in methodology employed but also (1) the lack of common objectives for these studies and (2) the differences in the universes represented in the participants from whom data were collected. There is little in common between any two of the studies, with the exception of the two by Bowman and associates, except for the general methodological approaches represented in the three groupings above. Because of these differences it is not possible to compare findings except in very general terms and except to note some trends.

A. Job Analyses. Among the five job analyses, the study by Rash ${ }^{30}$ reports health educators engaged in 46 different activities with the greatest amount of time concerned with three broad categories - administration, education, and public relations. In contrast, Derderian ${ }^{10}$ gives the percentages of time spent in several very specific kinds of activities, most of them concerned with the preparation of informational materials or communication of information. Giving consultant service also ranked high.

The trend away from dissemination of information and preparation of informational materials can be noted in the job analyses by Galiher and Wright ${ }^{21}$ only a few years later and especially in the Bowman and O'Rourke " study reported 15 years later. These two studies deal more specifically with functions of public health educators than the Rash and Derderian job analyses. As noted earlier, community organization was the dominating emphasis in health education in the 1950s when Galiher and Wright gathered data. Thus it is not surprising that they reported health educators engaged most frequently in community organizing activities such as working with professional groups, organizing lay groups, planning meetings, and supervising other staff and less frequently in activities concerned with 


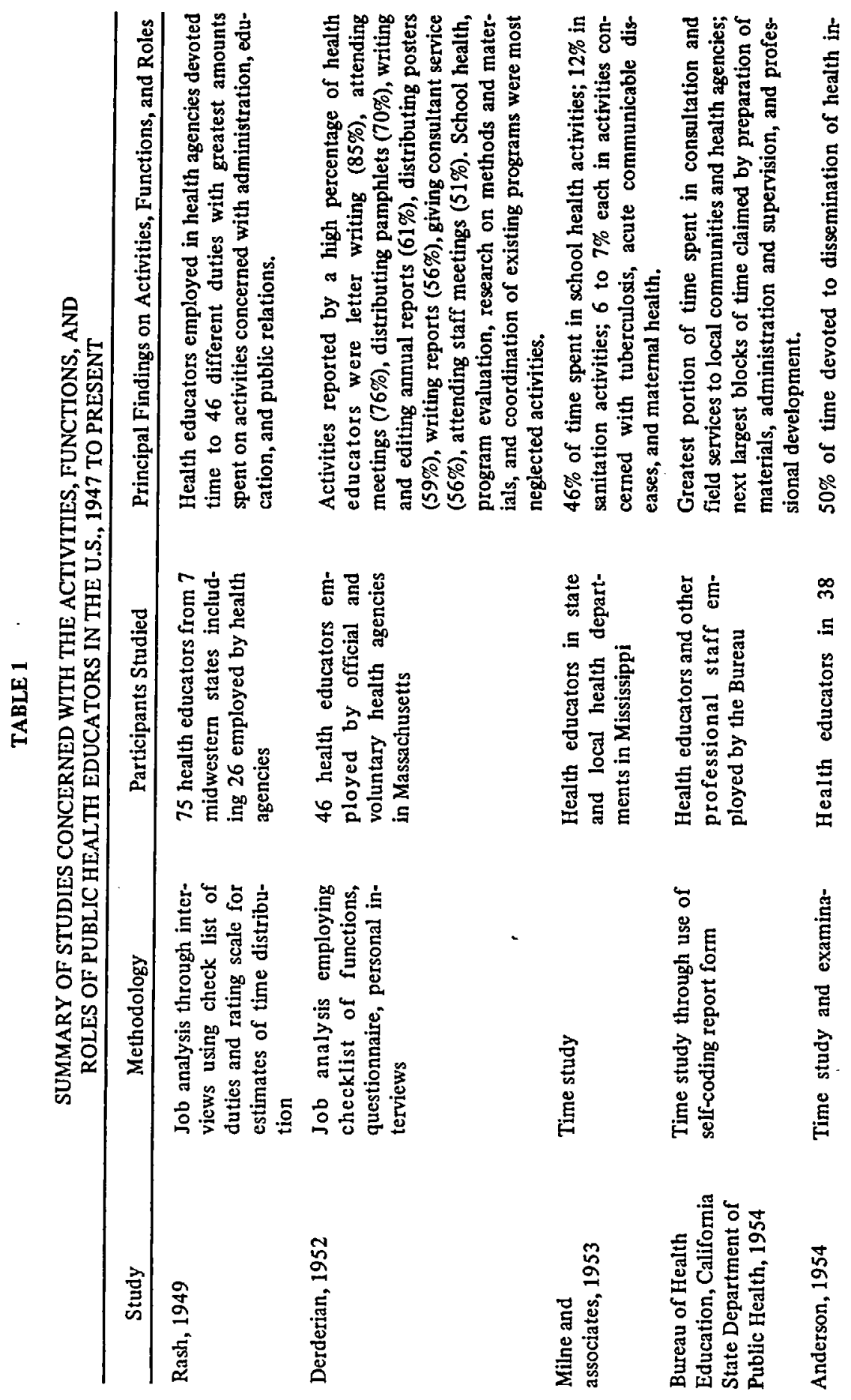




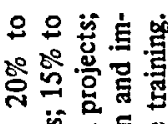

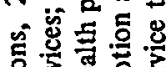
을 운 0 을 o

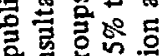

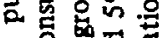

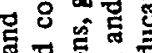

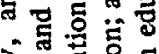

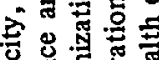

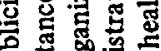
旁 50

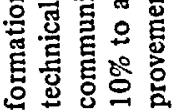

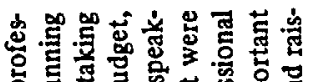

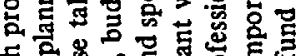
可

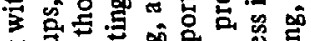

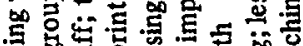

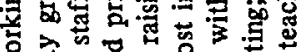

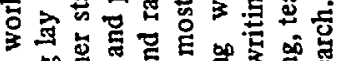
此

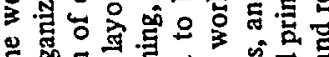

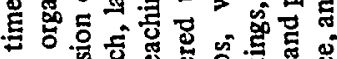
to

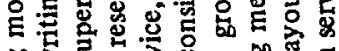

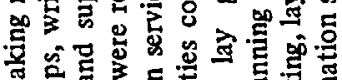

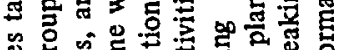

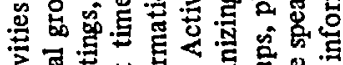

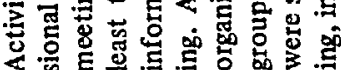

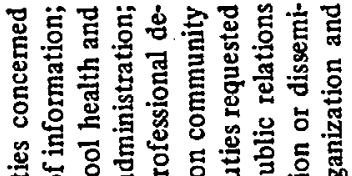

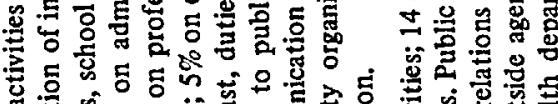

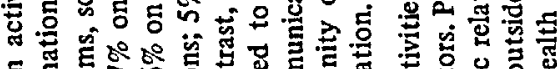
5.

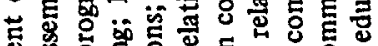
5

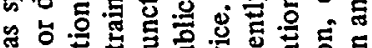

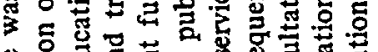

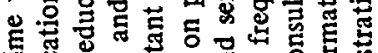
c s 4 政 栗

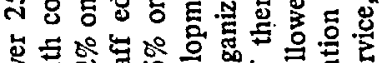

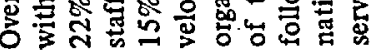

害䒠岁骂宫

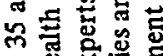
岁导 उ. 士음 要

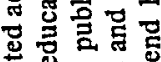

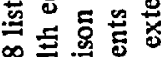

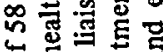
岁的敋 요월 5 焉.

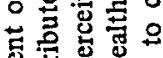
要密的 尊 要送 है

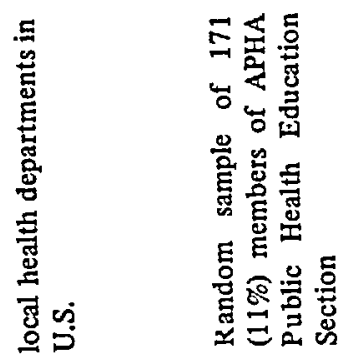

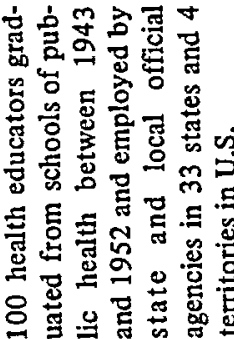

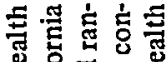
은

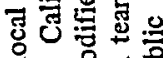
․․일 तิ

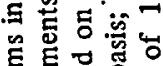

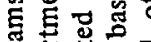

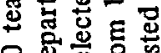

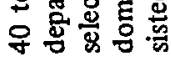

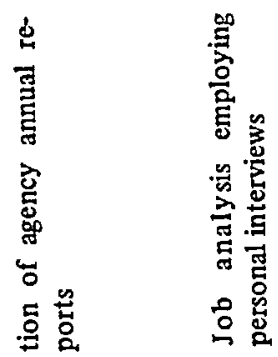

능요 명요

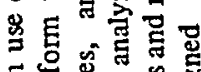

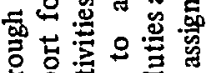

总

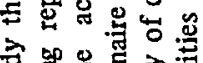

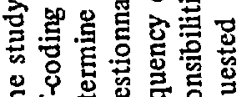

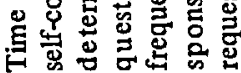

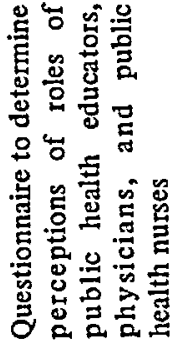

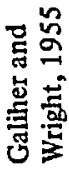

ลั

을
퐁 


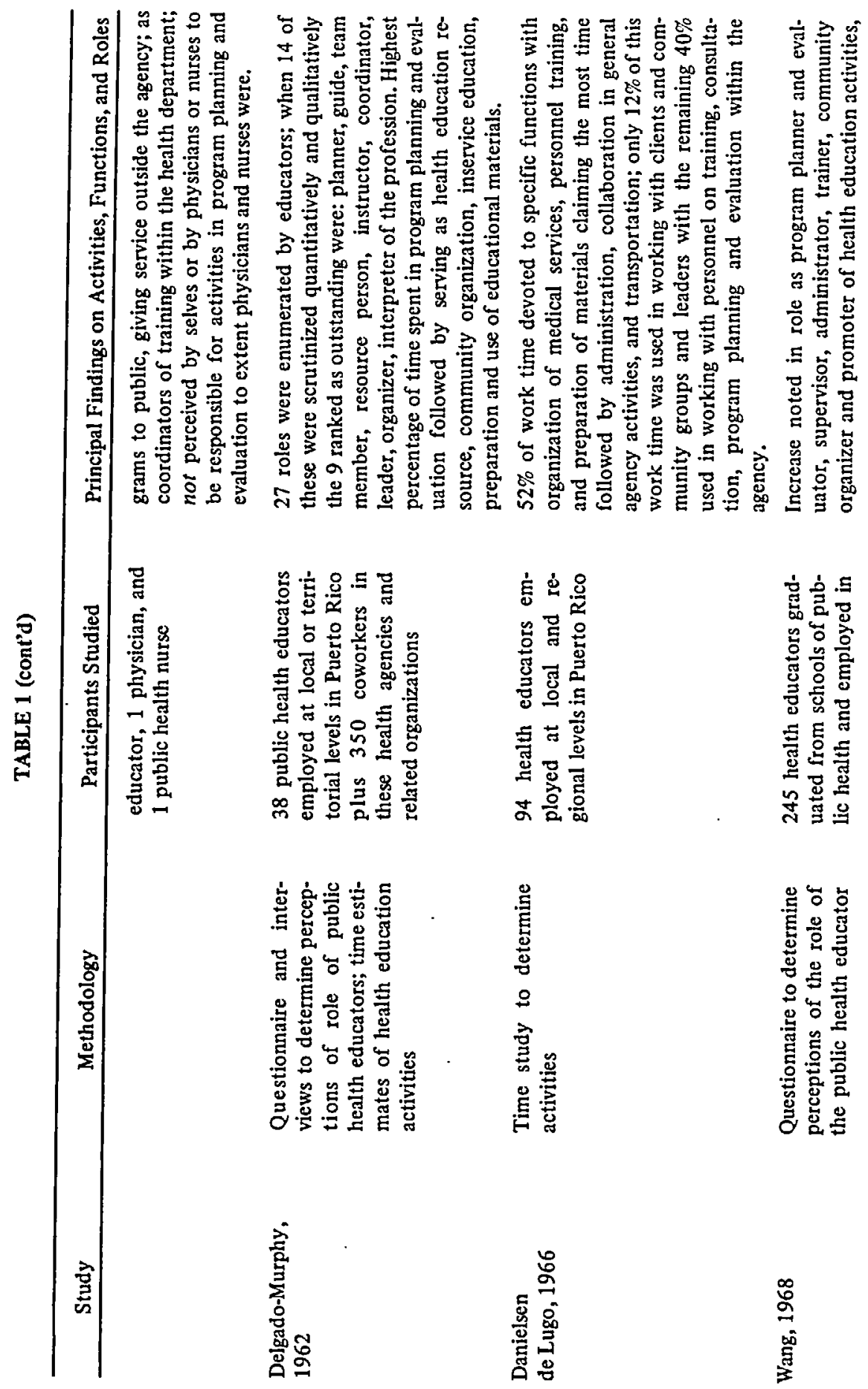




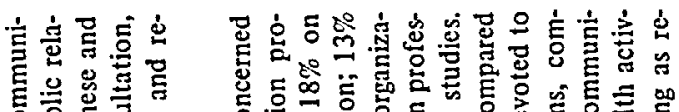

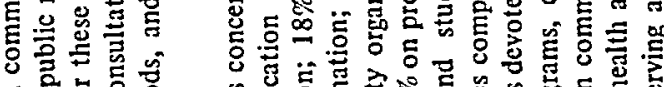

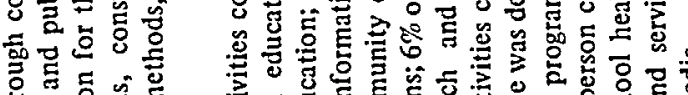

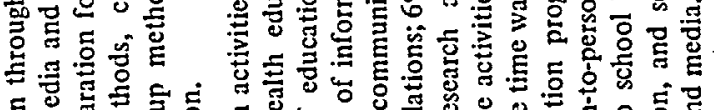

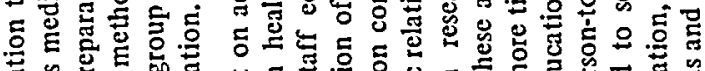

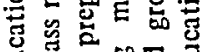

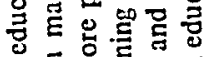
드 을 을 홍

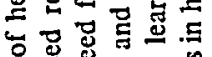
5

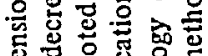

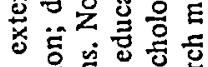

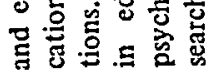

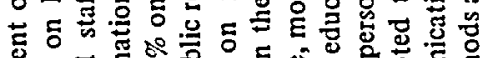

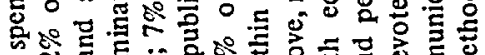
क्ष

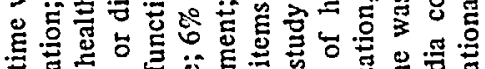

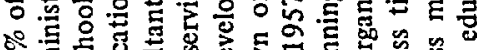

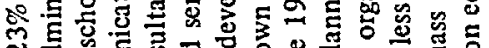

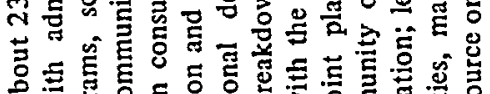

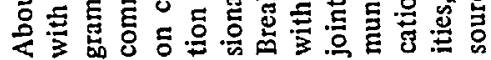

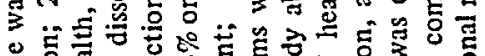

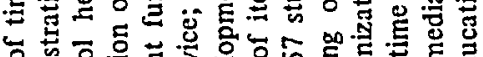

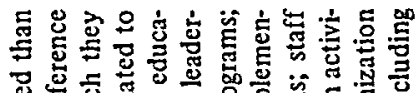

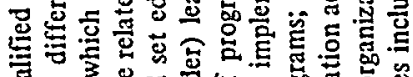

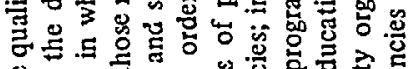

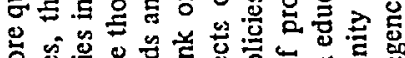

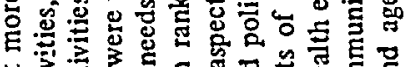
월 굴

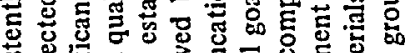
क्ष

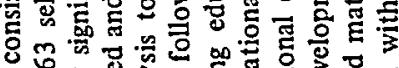

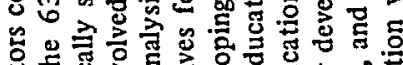
害

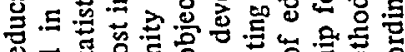
跑

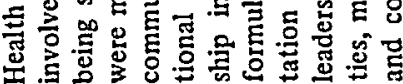

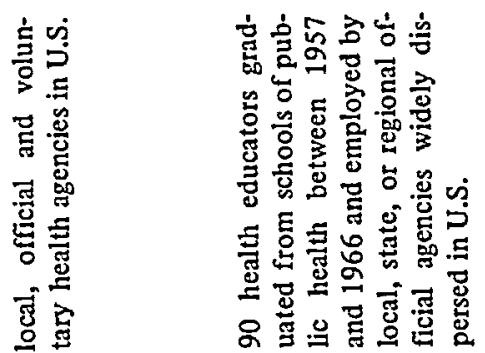

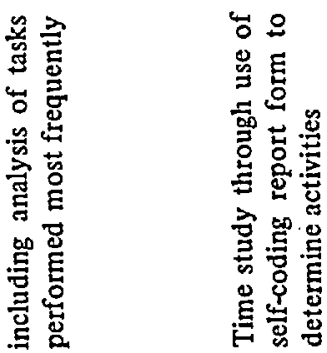

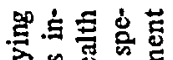
응

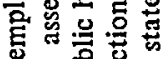
2 咅品 员. 둥.s 势

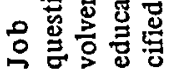

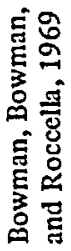

迹 


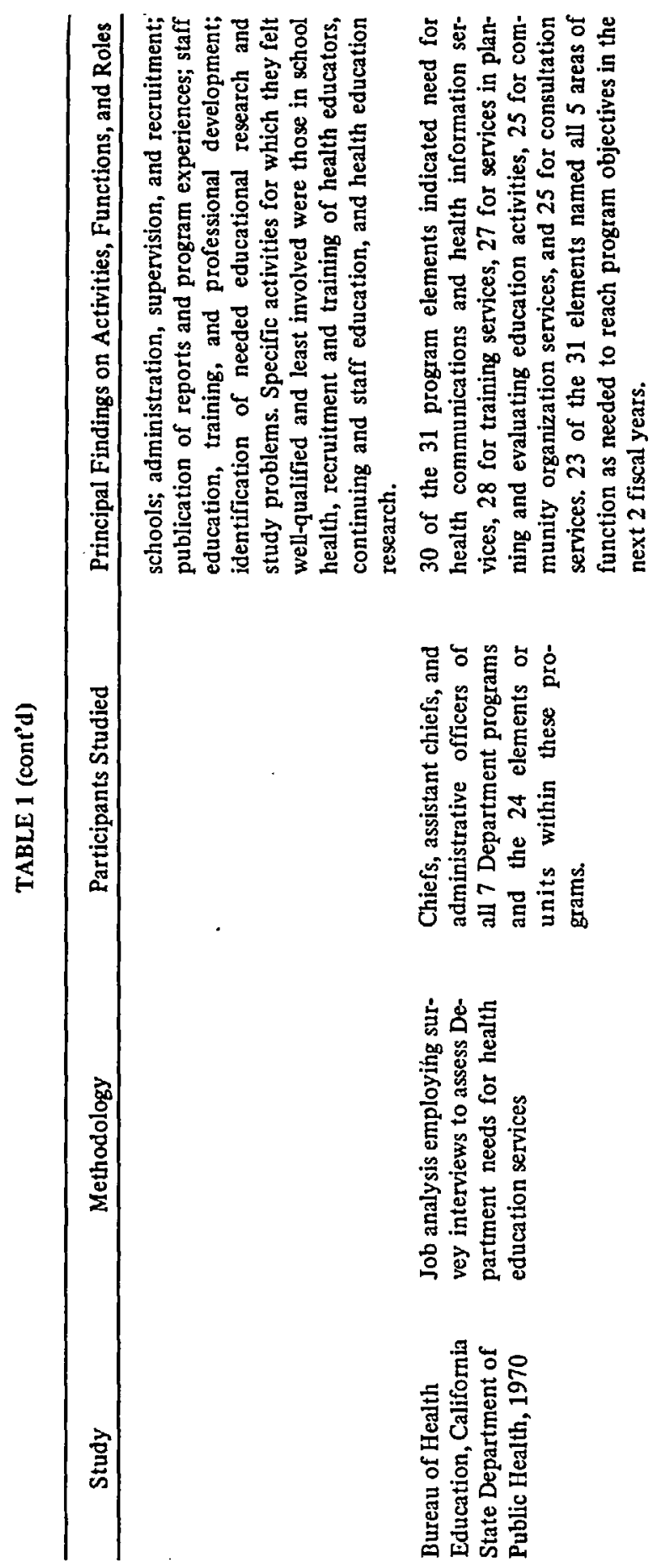


preparation of informational materials and dissemination of information such as layout and printing, provision of information services, and speaking.

The Bowman and O'Rourke study reflects the further shift away from dissemination of information, a lessening of community organization activity, and the impact of the emphasis on the behavioral approach and program planning and evaluation. Thus health educators were found to be most involved in carrying out functions concerned with community analysis and determinants of behavior, formulating educational objectives and policies, developing and implementing educational components of programs and evaluation procedures. They continued to be involved, but to a lesser extent, in functions concerned with community organization, training and staff education, and development of educational materials.

The job analyses conducted by the Bureau of Health Education in the California State Department of Public Health 14 in 1970 differs in objective from the other four. This was a needs study designed to provide criteria for assignment of public health educators and for the organization of health education resources with the department. Data were compiled in an attempt to identify educational activities required to reach department program objectives for the next two fiscal years. Although the survey sought data on only five areas of health educator functions (health communications and health information, training, planning and evaluation, community organization, and consultation), 62 activities in these five areas made up the survey items.

The fact that all but one of the program elements indicated need for health communications and health information services may reflect administrators' perceptions of the function of public health educators or established patterns in the department. However, the prominence given to training and to planning and evaluating and the lower position given to community organization and to consultation functions is indicative of the trend toward the emphasis in health behavior and program planning as functions of public health educators.

B. Time Studies. Except for the earliest study by Milne ${ }^{26}$ and his associates which focused on time spent in health department programs (school health, sanitation, tuberculosis, acute communicable diseases, maternal health, etc.), time studies have been concerned with specific functions or activities of public health educators. However, not only the disparities in study objectives and universes mentioned earlier, but also the differences in terminology and in categorization of functions makes comparisons difficult.

Anderson's ${ }^{s}$ findings support the thesis that public health educators were principally disseminators of information in early years. Half of their work time he found devoted to such activities with much lesser 
amounts to technical assistance and consultative services, community organization, administration, inservice training, and improvement of health education. However, the California Bureau of Health Education ${ }^{13}$ study, also reported in 1954 but with quite different objectives and a universe consisting of employees at the state rather than local level, found that consultation and field services to local health departments claimed the greatest amount of time followed by activities concerned with the preparation of informational materials, administration and supervision, and professional development.

Data gathered by Bowman ${ }^{10}$ for a study reported in 1957 found public health educators devoting one-fourth of their time to functions concerned with communication or dissemination of information, a somewhat lesser amount of time to education functions in community and school health programs including staff education and training. Lesser amounts of time were spent on functions concerned with administration, consultation, professional development, public relations, community organization and service. These findings reflect the strong emphasis on dissemination of information functions in the earlier era but do not show the impact of the community organization emphasis that might be anticipated in the mid-1950s.

The comparative study carried out by Bowman ${ }^{12}$ and others 12 years later indicated that administrative functions claimed only slightly less than one-fourth of the time of the public health educators to lead all categories of functions. Time devoted to education functions in community and school health programs including staff education and training continued at 22 percent, identical to the figure in the earlier study. A somewhat less amount of time was devoted to communication or dissemination of information functions, the leading category in the 1957 study. The amounts of time spent on functions concerned with consultation, community organization and service, public relations, and professional development differed little in the two studies but with some shifts in rank order. When specific functions within the larger categories in the two studies were compared, it was found that in the later study more time was spent on joint planning of health education programs, community organization, and person-toperson communication. Less time was devoted to school health activities, mass media communications, and serving as a resource on educational methods and media.

These comparative studies provide evidence of the trend away from dissemination of information and mass media in favor of more emphasis on community organization, program planning, and more personal communication. The latter may indicate the initial impact of the behavioral approach.

The time study by Danielsen de Lugo ${ }^{17}$ also appears to support these trends. No direct comparison of time spent on various functions 
is possible because of differences in the list of activities utilized. However, she found that $\mathbf{4 0}$ percent of work time was devoted to working with personnel on training, consultation, program planning and evaluation within the agency and 12 percent to working with clients and community groups and leaders - presumably much of this related to community organization. Among specific functions. personnel training and preparation of materials each claimed large amounts of time. Except as it is a part of the previously mentioned functions, dissemination of information apparently did not claim any large amount of time since the function listed as information service did not rank among those claiming substantial amounts of time.

C. Role Perceptions. Since the Arnold 'study sought to determine the role perceptions of physicians and public health nurses as well as public health educators, the findings differ from those reported in the Delgado-Murphy ${ }^{18}$ and Wang ${ }^{37}$ studies which were concerned with public health educator roles exclusively. Arnold reports agreement among the three groups of professionals on the roles of public health educators as (1) liaison public relations experts for the health department and outside agencies and organizations, (2) workers to carry and extend health department programs to the public, and (3) as coordinators of training within the health department. She reports that neither the self-perception of the educators or the perceptions of the other two professional groups indicated the public health educator to be responsible for program planning and evaluation to the extent the other two professions were perceived to be. Presumably this is intended to imply the degree of responsibility and does not exclude program planning and evaluation as a function of public health educators.

While Delgado-Murphy focused on the roles of public health educators, she utilized self-perceptions as well as the perceptions of coworkers in gathering data on the role of the educator. This study utilizes more generic designations for roles which could be applied to professional or non-professional workers in any setting. The nine roles perceived as outstanding for public health educators were those of planner, guide, team member, resource person, instructor, coordinator, leader, organizer, and interpreter of the profession. Estimates of time devoted to activities made only by the public health educators in the study indicate that the greatest amount of time was devoted to activities concerned with program planning and evaluation followed by serving as a health education resource, community organization, inservice education, and the preparation and use of educational materials.

In her study, Wang also focuses exclusively on the role of public health educators. However, she limits her study to the perceptions of these professional educators for the study data on roles. She also 
gathered data on tasks performed most frequently by these educators employed in local health agencies. Her findings note an increase in the public health educator roles as program planner and evaluator, supervisor, administrator, trainer, community organizer and promoter of health education activities, and extension of health education through communication. Also noted is a decreased role in mass media and public relations.

These three studies which utilized role perceptions as the principal methodology were carried out within a period of less than 10 years in the 1960s. Generalizing from their findings, one can note the increased emphasis in program planning and evaluation, responsibility for training and professional education programs, community organization and promotion of health programs, and perhaps administration and supervision as functions and responsibilities of public health educators. Noted too is the decrease in emphasis on functions related to dissemination of information and the use of mass media for communication.

Thus these studies support the trends noted earlier (1) away from functions concerned with dissemination of information and mass media communications, (2) toward functions related to community organization, and (3) more recently toward those concerned with program planning and evaluation and the more personal forms of communication (the roles of guide, team member, resource person, coordinator, interpreter).

Related to roles as team member and resource person is the study carried out by Martikainen. ${ }^{25}$ She focused solely on the perceptions held by administrative supervisors of the role of health education specialists in preparing other health workers in government agencies to cope with the health education aspects of their jobs. Her findings indicate considerable disagreement about the health education specialist's role in medical, nursing, and midwifery education, the preparation of environmental health personnel, and in post-graduate preparation of public health students. The health education specialist's role in these activities anticipated for the future varied in intensity of expectation. While these findings do pertain to the training role of public health educators, it is not possible to compare this study and the foregoing broader studies on role perceptions.

\section{Other Data on Activities of Public Health Educators}

Many health agencies, notably the local level tax-supported, routinely have compiled data on the activities and time alloted by staff members to programs and services in which the agencies engage. These data frequently are used to justify budget requests, expenditures, and proposed staff increases among other things, as well 
as to indicate the priorities and balance attempted in the provision of these programs and services. Data related specifically to the activities and functions of staff health educators are not discernible in many agencies especially where the focus is on programs and services rather than staff activities related to these.

Two which can be cited as examples of agencies in which specific data on the activities and time allotments of health education staff have been compiled are the San Diego County Health Department in California and the Omaha-Douglas County Health Department in Nebraska. San Diego pioneered in developing a methodology for this in the 1950s when Marion T. Bryant was Chief of the Bureau of Public Health Education. Modifications have been made from time to time to improve the methodology or to adapt it to program changes. In this agency each health education staff member codes (1) the time he devotes to any of the 15 program areas (sanitation, venereal disease, maternal and child health, etc.) in which the department engages and (2) the nature of the service he provided (consultation, program planning, community presentations, etc.) These data are summarized monthly and again for the fiscal year and used for several of the purposes cited above.

Data on Omaha-Douglas County health education activities have been compiled in the form currently in use since the late 1960s. This began as a department-wide effort to utilize a systems approach to program planning, evaluation, and budgeting. Modifications were made in the early 1970 s to provide improved methodology for cost analysis of department programs. The department engages in eight programs, one of which is health education. Each of the sub-programs under these is coded and is considered to have a health education component. Health education staff code their work hours daily by subprogram and by type of service provided (e.g., school contact, patient contact, consultation, inservice training, etc.). Monthly compilations provide data for program evaluation and cost analysis.*

No definitive studies are found in the literature which utilize data compiled routinely by agencies, as described above, to explore changes in the activities and functions of public health educators over time. However, the potential for such studies from data compiled month after month is evident. Some sorting of data would be necessary to separate the public health educators from other personnel on the health education staffs in many agencies. But this effort would provide

-The author is indebted to Merl I. Whorlow, Chief, Bureau of Public Health Education, San Diego County Health Department, San Diego, California and to Violet DuBois, Chief, Division of Health Education, Omaha-Douglas County Health Department, Omaha, Nebraska for information, sample forms, data summaries and other materials regarding these data-gathering systems $M r$. Whorlow and Miss DuBois recently retired from their pasitions in these agencies. 
the opportunity to examine the functions of public health educators and the utilization of health education manpower in health agencies different from the studies previously published and reported above.

\section{Functions of Public Health Educators}

\section{in Emerging Settings for Practice}

National health legislation enacted in the 1960s spawned many new health programs reflecting social change and new thinking regarding the delivery of health services. The past decade has witnessed many changes in life styles, rise of the ecology movement, escalation of substance abuse problems, concerns for patients' rights and human rights, stress on the accountability of health professionals and health programs, and recognition of the need for a national focus for health education and stepped up health education efforts at all levels, community through national. All of these movements, concerns, and interests have had a profound impact on the activities and responsibilities of health professionals including public health educators. Many positions in non-traditional health agencies have been established as a result of these recent developments.

Several emerging settings for public health education practice have become evident in the past decade. Among these settings is patient education in which public health educators are employed in hospital or clinic settings as well as in the outreach or follow-up programs for patients. Another setting is in health manpower training, especially for allied health personnel, and continuing education programs for health personnel on all levels. Health planning agencies, health maintenance organizations, health insurance plans, marketing programs and the like constitute others. There are also settings concerned with special groups such as rural cooperative extension services or child care agencies concerned with health education of preschool children and their parents. Others focus upon special problems such as ecology programs and dependency or substance abuse programs. Still others are concerned with educational technology such as self-instruction programs and health communications reflecting the host of recent advances in electronic communications. Others might be included.

Most of these represent settings in which a few unheralded health educators pioneered earlier. Some are new or reflect recent changes or new emphases. Many are settings in which the full potential for public health educator skills, competencies, and contributions have just recently been recognized.

In light of the many apparent changing or new roles and functions of public health educators in these emerging settings, and the difficulty in defining these, further studies are needed. However, most of these changes are of too recent origin or involve too few health educators to 
make such studies feasible. One exception is patient education. A number of studies concerned with the roles and functions of health educators in hospitals and clinical settings currently are underway in a number of universities. When completed and published, these should prove valuable in defining roles and functions in this setting. As more public health educators become involved in other emerging settings, similar studies should be undertaken.

\section{Implications for the Profession}

The movement of public health educators into a number of seemingly new-type positions in nontraditional settings appears to pose problems for the profession in defining its mission and relative role and status among other professions. Related to this are the problems posed for colleges and universities engaged in preservice education for public health educators and in inservice education for practitioners in this field. The number of choices for practice open to public health educators at present is far greater than at any time in the history of the profession.

The greater number of choices implies a greater number of roles and functions for public health educators. And this undoubtedly will be found to be true as studies are made of health educators employed in the new-type positions, or in positions in the more traditional employing agencies undergoing change too, if the focus is on the specific roles and functions carried out.

However, when one considers the tasks and responsibilities involved in health educator positions in the emerging settings for practice and in agencies adapting to change, many of the general roles and functions apparent in the studies reported for the 1950-1970 period are evident. For example, it is quite apparent that roles and functions concerned with program planning and evaluation, training and continuing education, consultation, person-to-person communication, administration and supervision, research and studies will be involved to some degree in all of the emerging settings for practice. Many of the settings also will require functions related to community organization and service, extension of health education through cornmunications and joint planning.

But these are the general categories. The specific roles and functions within each may be quite different from those in the past. For example, the community organization of the 1940s and 1950 s emphasized coordination of all agencies and groups in the problemsolving process as a method of education. Presently, community organization encompasses social action, advocacy, organizational development, and change agentry in general. Thus the specific roles and functions relating to this category will be quite different in any studies made in the future from those identified in the studies 
examined earlier. Undoubtedly, this will be true for other general categories of roles and functions as well.

Many of the emerging settings appear to reflect the behavioral emphasis in health education which arose in the 1960 s as recounted earlier. A greater knowledge of the determinants of health behavior and the development of educational strategies and tasks which apply this knowledge will be essential in specific roles and functions in patient education, health planning, ecology, dependency, substance abuse, training and continuing education programs - in fact, in all of the emerging settings for practice. Knowledge of behavioral determinants and strategies for their application will be important also to specific roles and functions related to organizational change, organizational development, and educational intervention.

As a final comment, one might point out that the specific roles and functions in such emerging settings as patient education, manpower training and continuing education, health education for preschool children and their parents, self-instruction, health communications programs, and others will place greater stress on the analysis of learning tasks, behavioral learning objectives, instructional methodology to achieve specific learning goals, and the evaluation of learning. Thus it appears that the roles and functions of public health educators in the future may become more truly those of teachers, instructors, educators - perhaps more so than at any time since the effective separation of school health and public health education as independent professional fields.

\section{REFERENCES}

1. American Public Health Association, Committee on Professional Education: Proposed report on educational qualifications of adult health educators. Am J Public Health 27:717-721, July 1937.

2. American Public Health Association, Committee on Professional Education: Proposed report on educational qualifications of health educators. Am J Public Health 33:998-1002, August 1943.

3. American Public Health Association, Committee on Professional Education: Proposed report on educational qualifications of community health educators. Am $\mathbf{J}$ Public Health 38:843-850, June 1948.

4. American Public Health Association, Committee on Professional Education:

5. Anderson EJ: Staff Office Concept of Health Education. Doctoral Dissertation. Buffalo, NY, University of Buffalo, 1956, pp 103-109, 137-144.

6. Arnold MF: Perception of professional role in the local health department. Public Health Rep 77:80-88, January 1962.

7. Biggs HM, Bolduan C: The tuberculosis campaign: Its influence on the methods of public health work generally. In Transactions of the Ninth Annual Meeting, National Association for the Study and Prevention of Tuberculosis, New York, 1913, pp 42-43.

8. Blake JB: The origins of public health in the United States. Am J Public Health 38:1539-1550, November 1948 . 
9. Bowman RA: Consistencies in the Preparation and Work of the Public Health Educator. Doctoral diseertation. Ann Arbor, University of Michigan, 1957, pp 10-19.

10. Bowman RA: Consistencies in the preparation and work of public health educators. Am J Public Health 45:219-228, February 1958.

11. Bowman RA, O'Rourke TW: Public Health Educators: Their Activities and Their Assessment of Their Qualification, unpublished study, University of Michigan School of Public Health, Ann Arbor, 1970.

12. Bowman RA, Bowman VA, Roccella EJ: Comparison of duties and responsibilities of public health educators, 1957 and 1969. Public Health Rep 86:551-559, June 1971.

13. California State Department of Public Health: Time Study by Professional Staff: A Study of Time Spent in Selected Activities, January 1-June 30, 1954. San Francisco, Bureau of Health Education, 1954, pp 1-6, mimeo.

14. California State Department of Public Health: Health Education Needs Survey. San Francisco, Bureau of Health Education, February 1970, 25 pp, processed.

15. Cavins HM: National Health Agencies. Washington, Public Affairs Press, 1945, pp 73-81.

16. Connolly MP: Organization of adult groups for health education. Am J Public Health 24:571-575, June 1934.

17. Danielsen de Lugo J: Time Study of the Functions of the Health Educator in Puerto Rico. San Juan, University of Puerto Rico, Department of Preventive Medicine and Public Health, 1966, processed.

18. Delgado-Murphy D: Development of Health Education in Puerto Rico: A Study with Particular Reference to Health Educator Roles in the Island-Wide Program. Doctoral dissertation. Chapel Hill, University of North Carolina, 1962.

19. Derderian LK: The Public Health Educator. Dactoral dissertation. Cambridge, Harvard University, 1952.

20. Derryberry M: Panel presentation, Annual meeting of Society for Public Health Education, Chicago, November 15, 1975.

21. Galiher CB, Wright JE: We study ourselves. Am J Public Health 45:807-810, June 1955.

22. Jean SL: Stars to steer by. Am J Public Health 41:963-970, August 1951.

23. Kleinschmidt HE: The birth of a section. Am J Public Health 38:1657, December 1948.

24. Mann H: Annual reports of the secretary of the board of education of Massachusetts, sixth report for 1842. In Life and Works. Boston, Lee and Shepard Publishers, 1891, pp 131-138.

25. Martikainen AH: A Study of the Role of the Health Education Specialists in the Preparation of Health Workers. Doctoral dissertation. Boston, Harvard University, 1965.

26. Milne JA et al: Time study of public health activities in Mississippi. Public Health Rep 68:378-390, April 1953.

27. Morgan LS: Health education in extra-cantonment zones. Am J Public Health 32:1209-1214, November 1942.

28. Morgan IS: Professional preparation for health educators. High Sch J 30:176-179, May 1947.

29. Morgan LS, Horning BG: The community health education program. Am J Public Health 30:1323-1330, November 1940.

30. Rash JK: An Analysis of Selected Professional Health Educators. Doctoral dissertation. Bloomington, Indiana University, 1959.

31. Rugen ME: History of the Public Health Education Section. Washington, American Public Health Association, 1972.

32. Shattuck L: Report of the Sanitary Commission of Massachusetts. Cambridge, Harvard University Press, 1948, p 310.

33. Society for Public Health Education: Subject Matter Outline: Health Education 
Specialist. Prepared for Professional Examination Service, APHA, 1964. 5 pp, mimeographed.

34. Society for Public Health Education: Statement of functions of community health educators and minimum requirements for their professional preparation with recommendations for implementation. Adopted by SOPHE Board, Mar 14, 1967, 23 pp, processed.

35. Temkin O: Health education through the ages. Am J Public Health 30:1095, September 1940.

36. Van Ingen P: The Story of the American Child Health Association. New York, The American Child Health Association, 1936, pp 8-25.

37. Wang VL: The Local Health Educator: His Perception of the Professional Role and Training Implications. Doctoral dissertation. Chapel Hill, University of North Carolina, 1968.

38. Winslow C: The Evolution and Significance of the Modern Public Health Campaign. New Haven, Yale University Press, 1923, p 53. 